\title{
The shutter-automatic machine throughput of the washing device of the water level automatic regulator
}

\author{
Mukaddas-Gaukhar Kadirova* \\ Tashkent Institute of Irrigation and Agricultural Mechanization Engineers, Tashkent Uzbekistan
}

\begin{abstract}
To determine the throughput of the automatic gate of the flushing device, which is part of the hydraulic automatic water level controller with flexible working bodies, developed by the author together with Ya.V. Bochkarev, experimental studies were conducted. They were carried out by the method of physical modeling of the model and nature on an experimental installation, with the installation of two models of an automatic shutter: a) with a fixed angle of inclination of the pressure board, b) with an automatic shutter in the form of a container consisting of a rigid board under pressure in front of it and a rubberized fabric, as part of an automatic water level regulator. Based on the results of these studies, formulas and dependencies were obtained to determine the flow rates without taking into account and taking into account the lateral outflows and lateral compression coefficients and the water flows passing through the automatic gate.
\end{abstract}

\section{Introduction}

The modern tendencies and scales of development of hydraulic engineering and land reclamation are put forward - the problem of effective management of the water level in irrigation systems. To maintain the required water level in front of the design of the partitions on the canal and to supply a given flow of water to the distribution canals, the design of partitions must be automated. Due to the massive use of shutters on partition structures of irrigation systems and their remoteness from power lines, among them, from the point of view of economic efficiency, structures using automatic hydraulic gates are most effective since they work using hydraulic energy of a moving water stream. They found the greatest application on partition structures of irrigation canals, structures developed and described in the works of Sh.S. Bobokhidze [1], Ya.V. Bochkarev [2], [3], [4], N.A. Zakusilov [5], O. G. Zatvornitsky [6], P. Kovalenko [7], E.E. Makovsky [8]. The main thing in these structures is a metal shutter (flat, segment, valve, sector) of one design or another, the requirement for them to have significant water level drops, preventing water overflow through the top of the shutter, the need for periodic mechanical cleaning of the space in front of the shutters from floating objects and debris, the need in capital structures.

*Corresponding author: mukaddas-gauhar1952@yandex.ru 
This, of course, is expensive and prevents their widespread introduction into production. Today, with the advent of soft rubberized fabrics, soft (flexible) designs of automatic hydraulic closures have appeared. They combine the properties of soft (flexible) materials with traditional rigid materials described in the works of M.-G.A. Kadirova [9], I.A. Petrov [11], B.I. Sergeev [12], B.I. Sergeev, P.M. Stepanov, V.V. Shumakov [13], [14]. However, in these designs, the disadvantage is either the need to flush the space in front of the structures from deposits or the need for periodic mechanical cleaning of floating bodies and debris from the space in front of the shutter. The designs of these shutters are cheap, economical; they are not metal-consuming, lightweight, environmentally friendly, maintainable; as needed, they can be mobile, portable, and collapsible. To eliminate the aforementioned drawbacks of automatic shutters, automatically maintain a constant water level before the construction, automatically pass floating bodies and wash out sediments deposited in front of the construction, we, together with Professor Ya.V. Bochkarev, proposed an automatic water level controller [15]. It combines the properties of soft (flexible) materials with traditional rigid materials. An integral part of this automatic water level regulator is an automatic flush shutter with flexible working elements, consisting of a container formed by a rigid pressure shield and a soft tissue communicating with the container of the main shutter with an opening between them [21-30]. This automatic shutter is installed in the flushing device formed by the bottom of the main shutter and the bottom of the channel. To determine the flow rate of the flushing water that passed through the automatic flushing shutter [15], it is necessary to know its throughput. For this, his experimental studies were set and carried out.

\section{Materials and Methods}

The study was carried out by the method of physical modeling using the criterion of geometric similarity between the model and nature. Modeling of the investigated phenomena was carried out according to the criteria of Froude's gravitational similarity and dynamic similarity of forces. The scale of models to nature is taken 1: 4 .

The experimental setup consisted of a tray $10 \mathrm{~m}$ long, $1.0 \ldots 0.5 \mathrm{~m}$ high, $0.378 \mathrm{~m}$ wide. The maximum flow rate of water supplied to the tray was $0.0561 \mathrm{~m}^{3} / \mathrm{s}$. The tray had a closed water supply system, which was supplied by a pump.

\section{Results and Discussions}

To study the throughput of an automatic sediment flushing shutter with flexible working bodies, 2 models were studied:

a) from the pressure side in the form of a rigid board made of transparent organic glass with a thickness of $0.006 \mathrm{~mm}$ with a fixed angle to the horizon in the range from [tetta] = 0.611 radian to [tetta] $=0$ radian, in Figure 1, a;

b) in the form of an automatic shutter for washing off precipitation in the form of a container formed by a rigid board made of transparent plexiglass with a thickness of 0,006 $\mathrm{m}$ with an unfixed angle to the horizon, varying from [tetta] $=0,611$ radians to [tetta] $=0$ radians, and a soft rubberized cloth as part of an automatic water level controller, Figure 1, b.

One of the models (Figgure 1, a) consists of a rigid board 1, installed with a maximum angle of inclination to the horizon $[\text { tetta }]_{\max }=0.785$ radians into the hole between the walls of the tray the bottom of the tray, and the diaphragm 14. The rigid board is made of transparent plexiglass $0.006 \mathrm{~m}$, length $0.095 \mathrm{~m}$, width $0.376 \mathrm{~m}$., The diaphragm does not let water through. Rigidly fixed in the upper part of the tray with a width of $0.378 \mathrm{~m}$ between 
the walls of the tray, the width of the opening is $0.378 \mathrm{~m}$, the height of the opening is 0.067 m.

The other model was a shutter-an automatic sediment washing machine as part of an automatic water level controller. The model of the automatic gate for washing sediments consisted of a container 3 with a pressure part in the form of a rigid shield 1, forming together with an elastic material made of rubberized fabric (shell) 2, with a length of $0.09 \mathrm{~m}$ and a width of $0.37 \mathrm{~m}$ on the non-pressure side and passing into the side elements of the automatic gate. This capacity of the automatic sediment flushing gate 3 is attached to the bottom of the main gate 7 of the automatic water level controller. The rigid board of the gate-automatic cleaning of deposits 1 is made of organic rectangular glass with a width of $0.372 \mathrm{~m}$ and a length of $0.095 \mathrm{~m}$, forming in the closed state the maximum angle [tetta]max $=0.785$ radians to the horizon. The automatic sediment cleaning gate covers the opening with a width of $0.378 \mathrm{~m}$ and a height of $0.067 \mathrm{~m}$ between the bottom of the tray and the bottom of the main gate of the automatic water level controller.

The capacity of the automatic gate for cleaning deposits 3 was communicated with the capacity of the main gate by an opening 8 with a diameter of $0.04 \mathrm{~m}$.

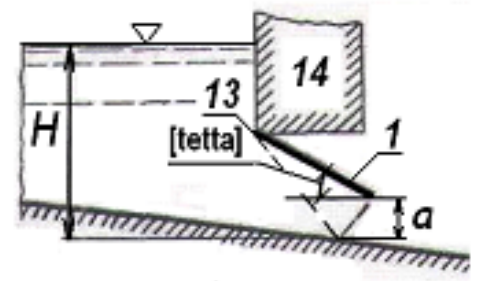

a)

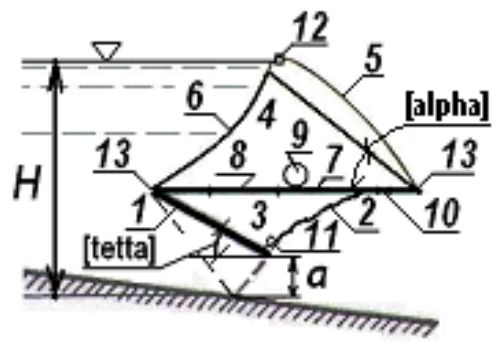

b)

Fig. 1. The models under study: a) with a pressure part in the form of a rigid board made of transparent organic glass with a thickness of $0.006 \mathrm{~m}$, with a fixed angle [tetta] to the horizon, set in the range of 0.785 radians up to 0 radians; b) in the form of an automatic gate for cleaning deposits, which is a container consisting of a pressure part in the form of a rigid board made of transparent organic glass with a thickness of $0.006 \mathrm{~m}$, with an unfixed angle [tetta] to the horizon, varying from 0.785 radians to 0 radians on the pressure side and rubberized fabric on the non-pressure side and sides. 1 is rigid board, 2 is rubberized fabric, 3 is shutter capacity-automatic cleaning of deposits, 4 is capacity of the main shutter of the automatic water level controller, 5 is rigid spillway part of the main shutter of the automatic water level controller, 6 is rubberized fabric, 7 is the rigid bottom of the main gate of the automatic water level controller, 8 is a hole that communicates the capacity of the gate-automatic cleaning of deposits with the capacity of the main gate of the automatic water level controller, 9 is the opening of the water pipe from the device for fixing the water level in the channel in front of the automatic water level controller, 10 is the drain hole from the tank of the main gate of the automatic water level controller, 11 is the drain hole from the tank of the automatic gate of cleaning of deposits, 12 is the hole for air outlet from the tank of the main gate of the automatic water level controller. 13 is the flexible connection made of rubberized fabric.

The main gate of the automatic water level controller, to the bottom of which an automatic gate for washing precipitation was attached, was modeled as a container consisting of a horizontal bottom of the main gate 7 , made in the form of a box with a height of $0.04 \mathrm{~m}$, a width of $0.378 \mathrm{~m}$, a length of $L_{k o r}=0.54 \mathrm{~m}$, a rigid spillway part 5 with a chord length of $L_{x}=0.38 \mathrm{~m}$, a non-vacuum profile covered with an elastic material made of rubberized fabric (shell), passing into the side elements of the main gate and its pressure part 6 length $L_{o b}=0.38 \mathrm{~m}$. At the same time, the maximum elevation angle of the chord of the spillway part of the main gate relative to the horizon was [alpha $]_{\max }=0.611$ radians. The bottom of the main gate was installed at the height of $0.067 \mathrm{~m}$ from the bottom of the tray. 
Thus the automatic sludge flushing shutter could cover the $0.067 \mathrm{~m}$ high opening between the bottom of the tray and the bottom of the main gate of the automatic water level controller.

Filling the tank of the main gate and through its hole 8 in the bottom of the tank of the gate-automatic cleaning of deposits was carried out from a pipe with a diameter of $0,025 \mathrm{~m}$, adjacent to the box of the bottom of the main gate through the side wall of the tray and supplying water from the tank of the device for fixing the water level in the channel in front of the automatic water level controller. To remove the air when filling the tank 4 of the main gate, an air outlet with a diameter of $0.006 \mathrm{~m}$ was made in the upper part of the spillway part of the main gate.

Water was drained from the tank of the main gate through a drain hole 10 with a diameter of $0.016 \mathrm{~m}$, made in the bottom of the main gate and through a drain hole 11 with a diameter of $0.005 \mathrm{~m}$, made in an elastic material made of rubberized fabric (cover) of the gate-automatic cleaning of deposits from its non-pressure side. The control of the water level in the tray before the automatic water level controller was carried out using a device for fixing the water level in the tray at different water costs supplied to the tray. The device for fixing the level in the tray in front of the automatic water level controller was a container made with a base size of $0.1 \mathrm{~m} \times 0.1 \mathrm{~m}$, made of organic glass in the form of a rectangular prism. It was installed near the side wall of the tray.

The capacity of the device for fixing the water level was communicated with the capacity of the tray in front of the automatic water level controller by a pipe with a diameter of $0,04 \mathrm{~m}$, the entrance of which was located at a distance of $1.5 \mathrm{~m}$ in the tray to the location of the main gate. The float of the device for fixing the water level was made of foam and mounted on a vertical centered rod, at the lower end of which a conical valve was installed, which, at a given level in front of the automatic water level controller, could partially or completely block the pipe hole with a diameter of $0.025 \mathrm{~m}$, communicating with the capacity of the main gate of the automatic water level controller. This choice was made due to the highest efficiency of such a model in preliminary studies.

Modeling of the rubberized fabric of the gate-automatic cleaning of deposits and the main gate of the automatic water level controller was carried out according to its maximum linear tension. This question is considered in the works of A. P. Nazarov [18, 19].

The main part of the experiments was carried out with a consistent increase in costs. All parameters were measured after 15 minutes...20 minutes after changing the flow rate or any of the dimensions. At this time, the tray was set to a constant flow mode.

The model is shown in Figure 1, a, was studied to determine the flow rate at the outflow from under the inclined flat board in the absence of lateral outflows.

The studies were conducted at fixed angles: [theta] $=0.105$ radians; 0.174 radians; 0.262 radians; 0.349 radians; 0.436 radians; 0.523 radians; 0.611 radians; 0,698 radians. The interval of change of the fixed angle was taken in the range from [tetta] $=0.070$ radians to [tetta] $=0.087$ radians to take into account the disorder of the points when constructing the dependence $\mu=\mathrm{f}(\mathrm{a} / \mathrm{H})$. The flow rate passing through the tray was measured using a Chipoletti measuring spillway, the water level was measured using shpitzenzooms, the angle of inclination of the flat board was rigidly fixed by it in the side walls of the hole on which it was installed when fixing the angle was measured by a protractor.

The flow coefficient was determined by the well-known formula for the outflow from the holes [17].

$$
Q=\mu \cdot a \cdot b_{p} \cdot \sqrt{2 \cdot g \cdot(H-\varepsilon \cdot a)}
$$


The factor of vertical compression is defined as $\varepsilon=f(a / H$, [tetta]) under the schedule on a figure 2, $a$ is size of opening of a board, $b_{p}$ is width of an aperture, $H$ is a pressure over the horizontal plane passing through a mark of a bottom of an aperture.

On the basis of mathematical processing of results of these researches, schedules of dependences $\mu=\mathrm{f}(a / H)$ have been constructed. At various corners of opening: [tetta] = 0.105 radian; 0.174 radian; 0.262 radian; 0.349 radian; 0.436 radian; 0.523 radian; 0.611 radian; 0,698 radian, in the absence of the lateral expirations, presented on a figure 3 .

From these schedules it is visible that in a change range $a / H=0.2 \ldots 0.75$ factor of the expense $\mu$ depending on an angle of slope of a flat board to horizon changes in следующиз limits at [tetta] $=0.105$ radian, $\mu=0.923 \ldots 0.920$; at [tetta] $=0.174$ radian, $\mu=0.903 \ldots$ 0.891 ; at [tetta] $=0.262$ radian, $\mu=0.864 \ldots 0.868$; at [tetta] $=0.349$ radian, $\mu=$ $0.833 \ldots 0.840$; at [tetta] $=0.436$ radian, $\mu=0.811 \ldots 0.817$; at [tetta] $=0.523$ radian, $\mu=$ $0.787 \ldots 0.795$; at $[$ tetta $]=0.611$ radian, $\mu=0.763 \ldots 0.780$; at [tetta $]=0.698$ radian, $\mu=$ $0.744 \ldots 0.761$.

To determine the flow rate of lateral exhalations in the study of the automatic gate of the washing device of the automatic water level controller, the model is shown in Figure 1, b. In the study, the total flow rate going through the tray was measured by the Chipoletti spillway, flow rates up to $0.056 \mathrm{~m} 3 / \mathrm{s}$ were passed through the tray, the initial state was assumed when there was no flow during the transit when the span was blocked.

The flow rate passing through the main gate of the automatic water level regulator, taking into account the lateral exhalations, was determined by the formula:

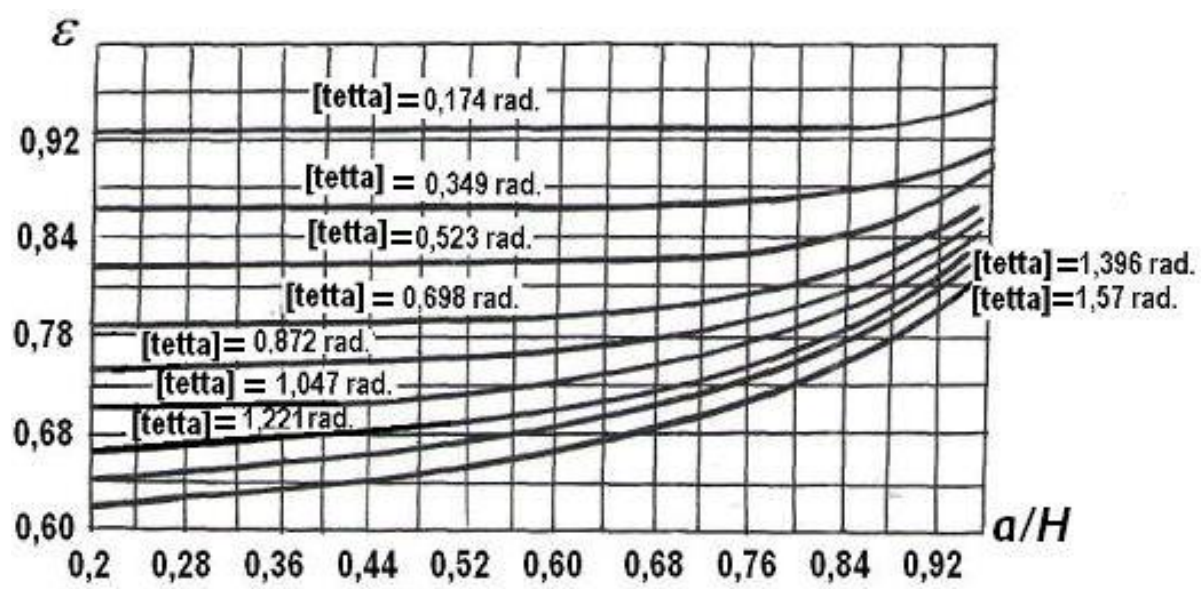

Fig. 2. The dependence schedule $\varepsilon=\mathrm{f}(a / H$, [tetta] $)$ for definition factor of vertical compression $\varepsilon$ at the expiration from under a flat board at the fixed angle of slope of a board [tetta] (in the absence of the lateral expirations). 


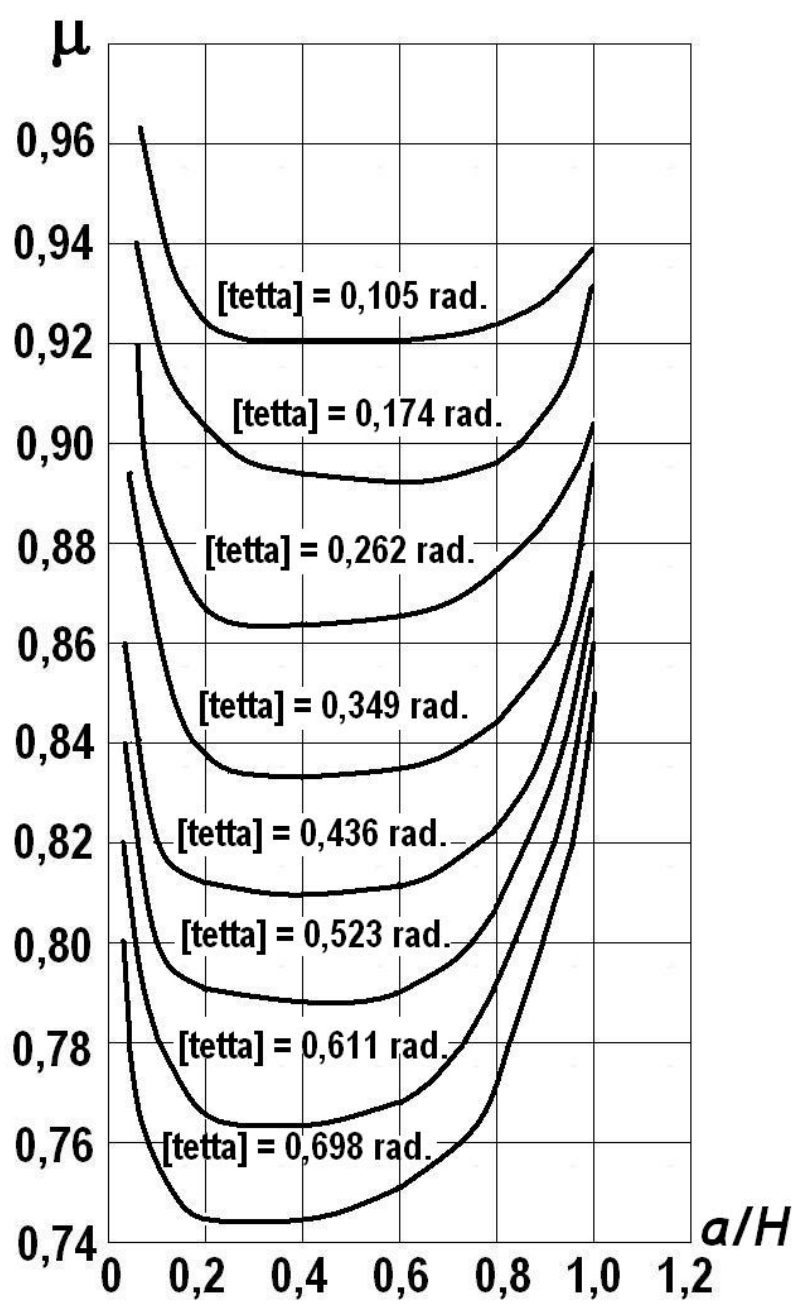

Fig. 3. Dependence schedules $\mu=\mathrm{f}([$ tetta $], a / H)$ at the expiration from under a flat board at the fixed angle of slope of a board (in the absence of the lateral expirations).

$$
Q_{p}=m_{p} \cdot b \cdot h \cdot(2 \cdot g \cdot h)(2 \cdot g \cdot h)^{0.5}
$$

Where $\mathrm{b}$ is width of the flight blocked by a shutter; $\mathrm{h}$ is pressure over a shutter crest; $\mathrm{g}$ is gravity acceleration, $m_{p}$ is the resulted factor of the expense defined under the following empirical formula of the author [10].

$$
m_{p}=-28.07\left(h / H_{z}\right)^{3}+25.263\left(h / H_{z}\right)^{2}-7.579\left(h / H_{z}\right)+1.2579
$$

Flow from under the shutter flushing device in the absence of lateral outflow was determined by the formula (1) where $\mu$ is the coefficient of flow determined according to the schedule in Fig.3, $\varepsilon$ is the coefficient of vertical compression, determined based on 
theoretical research Zhukovsky N. E. [20], developed by E. Makovsky, [8] and data [17], are shown in a graph in Fig. 2.

The flow rate of the lateral exhalations of the automatic shutter of the automatic water level regulator was determined as

$$
Q_{3}=Q-Q_{1}-Q_{2}
$$

On the basis of the given spent researches schedules $\varepsilon=f_{1}(a / H)$ on a figure 4 have been constructed; $\mu=\mathrm{f}_{2}(a / H)$ on a figure 5 and $\mathrm{Q}_{2} /\left(\mathrm{Q}_{2}+\mathrm{Q}_{3}\right)=\mathrm{f}_{3}(a / H)$ on a figure 6 .

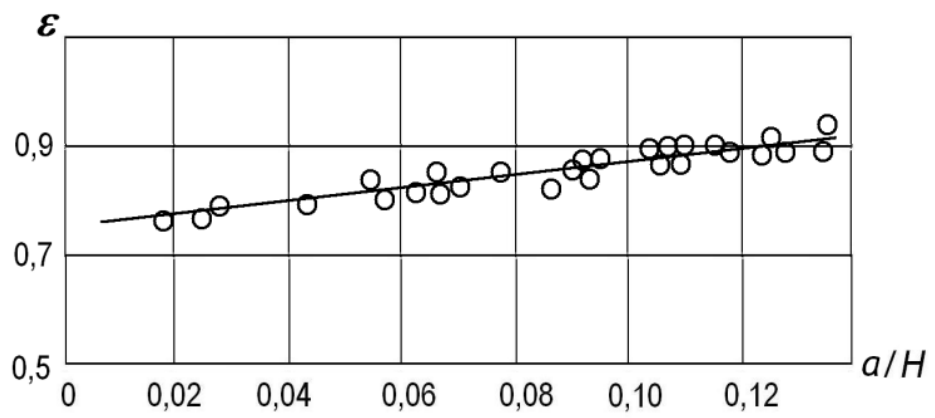

Fig. 4. The dependence schedule $\varepsilon=\mathrm{f}_{1}(a / H)$.

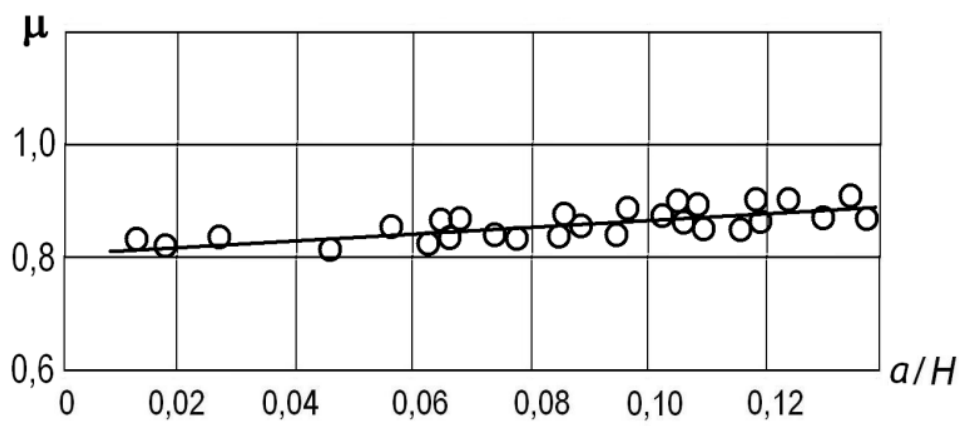

Fig. 5. The dependence schedule $\mu=f_{2}(a / H)$.

By mathematical processing of experimental researches by a method of final differences at $0.01 \leq a / H \leq 0.17$ following dependences taking into account the lateral expirations are received:

$$
\begin{aligned}
& \mu=0.58 \cdot a / H+0.8 \\
& \varepsilon=1.1 \cdot a / H+0.76 \\
& Q_{2} /\left(Q_{2}+Q_{2}\right)=0.89-0.13 \cdot a / H
\end{aligned}
$$

From the formula (5), it is possible to receive by algebraic transformations

$$
Q_{3}=[(0.11+0.13 \cdot a / H) /(0.89-0.13 \cdot a / H)] \cdot Q_{2}
$$

Where $Q_{3}$ is the expense of the lateral expirations of a shutter of the washing device of an automatic regulator of a water level, $Q_{2}$ is the expense of the expiration from under a shutter 
of the washing device of an automatic regulator of a water level without the lateral expirations.

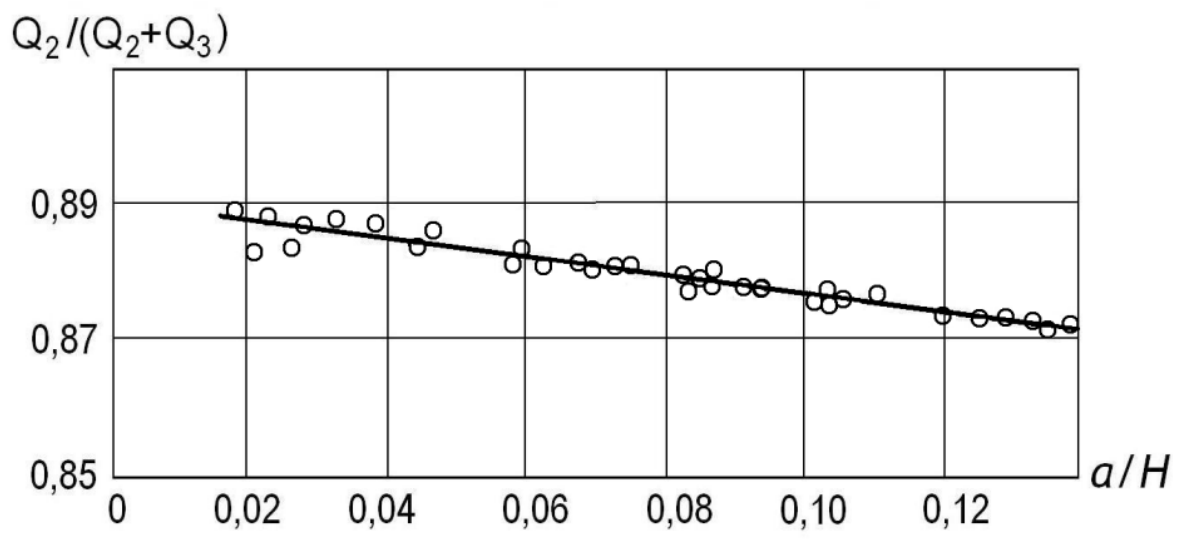

Fig. 6. The schedule of dependence $\mathrm{Q}_{2} /\left(\mathrm{Q}_{2}+\mathrm{Q}_{3}\right)=\mathrm{f}_{3}(a / H)$.

Based on (5), the total flow rate through the automatic sludge cleaning gate of the automatic water level controller will be

$$
Q_{2}+Q_{3}=Q_{2} /(0.89-0.13 \cdot a / H)
$$

\section{Conclusions}

1. Values of the factor of the expense $\mu$ at the expiration from under a shutterautomatic machine of the washing device in the absence of the lateral expirations tend to increase with corner reduction between a pressure head side of water containing shutterautomatic machine of the washing device and horizontal that speaks increase in the height of a water throughput aperture and factor of vertical compression $\varepsilon$.

2. At the expiration from under a shutter-automatic machine of the washing device with relation increase $a / H=0.01 \ldots 0.17$, the compression factor $\varepsilon$ increases under the law of a straight line (4), $\varepsilon=0.771 \ldots 0.947$.

3. With relation increase $a / H=0.01 \ldots 0.17$ at the expiration from under a shutterautomatic machine of the washing device, the expense factor $\mu$ increases under the law of a straight line (3), $\mu=0.806 \ldots 0.899$.

4. The Relation of the expense of the expiration from under a shutter-automatic machine of the washing device of an automatic regulator of water level $\mathrm{Q}_{2}$ to the sum of expenses of the expiration from under a shutter-automatic machine of washing device $\mathrm{Q}_{2}$ and lateral expirations $\mathrm{Q}_{3}$ decreases with relation increase $a / H=0.01 \ldots 0.17$ under the law of a straight line (5), $\mathrm{Q}_{2} /\left(\mathrm{Q}_{2}+\mathrm{Q}_{3}\right)=0.889 \ldots 0.868$.

\section{References}

1. Bobokhidze Sh.S. Hydraulic's automation of water distribution on irrigating systems. M: The Ear. p. 248, (1973)

2. Botchkarev J.V. Hydraulic automation of water distribution on irrigating systems. Frunze: Kyrgyzstan. p. 264, (1971) 
3. Botchkarev J.V. Operational hygrometry and automation of irrigating systems. M: Agropromizdat. p.173, (1987)

4. Botchkarev J.V. Hydroautomatics in irrigation. M: The Ear. p. 187, (1978)

5. Zakusilov N.A. Automation of irrigating systems and its economic efficiency. Frunze: Ylym. p. 165, (1975)

6. Zatvornitsky O.G. Constructions from soft covers in hydraulic engineering building. M: Energiya. p. 143, (1975)

7. Kovalenko P.I. Avtomatization of meliorative systems. M: The Ear. 1983. p. 304

8. Makovsky E.E. Automation of hydraulic engineering constructions in systems of cascade regulation of expenses of water. Frunze: Ylym. p. 302, (1972)

9. Kadirova M.-G.A. Level regulation on partitioning off constructions by means of a hydraulic automatic regulator of the level combined with a shutter - automat of cleaning of soil, International scientific and practical conference "Science, education and innovation for agro - industrial complex: problems and prospects" pp. 135-139. Tashkent, (2019)

10. Kadirova M G. Throughput of the water of shutter with flexible working bodies, IOP Conf. Ser.: Mater. Sci. Eng. 883 012019, (2020)

11. Petrov I.A. Application of filled designs from synthetic materials in hydraulic engineering building, p. 23, Novocherkassk, (1972)

12. Sergeev B.I. More light hydraulic engineering constructions. Dnepropetrovsk: Dnepropetrovsk institute of Agriculture, p. 104, (1983)

13. Sergeev B.I., Stepanov P.M., Shumakov V.V. Flexible designs in hydraulic engineering building. M.: The Ear. p. 100, (1984)

14. Sergeev B.I., Stepanov P.M., Shumakov V.V. Soft of a design a new kind of hydraulic engineering constructions. M: The Ear. p.88, (1971)

15. JA.V. Botchkarev, M.-G.A. Kadirova. Certificate of outhorship 665051 (USSR). Automatic regulator of water level, Published in B.I. № 20, (1979)

16. Ofitserov A.S. Spillway hydraulics. M: ONTI. p. 153, (1938)

17. Kiselyov P.G, Altshul A.D., Danilchenko N.B., Kasparson A.A., Krivchenko G I., Pashkov, Slissky S.M. Director by hydraulic calculations. pp. 63-70, (1974)

18. Nazarov A.P. Experimental research of throughput of soft spillways, Works by THEM, coll.: "Hydraulic engineering constructions of meliorative systems". Т. ХШ. Edition 1, pp. 223-226, Novocherkassk, (1973)

19. Nazarov A.P., Sergeev B.I. Throughput of soft filled spillways, Collection of papers. "Hydraulic engineering constructions of meliorative systems". T. XIV, Edition 6. pp. 119-129. Novocherkassk, (1973).

20. Zhukovsky N.E. Modification of a method of Kirhgoffa for definition of movement of a liquid in two measurements at the constant speed given on an unknown line of a current. Full coll. of books, 4, (1936)

21. Bazarov D., Markova I., Sultanov S. and Kattakulov F. Dynamics of the hydraulic and alluvial regime of the lower reaches of the Amudarya after the commissioning of the Takhiatash and Tuyamuyun hydrosystems. IOP Conf. Ser. Mater. Sci. Eng. 1030, 012110 (2021).

22. Bazarov D. and Vokhidov O. Extinguishing Excess Flow Energy in Spillway Structures. In book: Proceedings of EECE 2020, LNCE 150, pp. 535-545, (2021) DOI: 10.1007/978-3-030-72404-7_52

23. Krutov A., Choriev R., Norkulov B., Mavlyanova D. and Shomurodov A. Mathematical modelling of bottom deformations in the kinematic wave approximation. IOP Conf. Ser. Mater. Sci. Eng. 1030, 012147 (2021). 
24. Bazarov D., Vatin N., Obidov B., and Vokhidov O. Hydrodynamic effects of the flow on the slab of the stand in the presence of cavitation. IOP Conf. Ser. Mater. Sci. Eng. 1030, 012110 (2021).

25. Bazarov D., Norkulov B., Vokhidov O., Uljaev F., Ishankulov, Z. Two-dimensional flow movement in the area of protective regulatory structures. IOP Conf. Ser. Mater. Sci. Eng. 890, 012162 (2020)

26. Obidov B., Vokhidov O., Tadjieva D., Kurbanova, U., Isakov A. Hydrodynamic effects on the flow elements of the downstream devices in the presence of cavitation. IOP Conf. Ser. Mater. Sci. Eng. 1030, 012114 (2021).

27. Krutov A., Norkulov B., Nurmatov P., Mirzaev M. Applicability of zero-dimensional equations to forecast nonconservative components concentration in water bodies. IOP Conf. Ser. Mater. Sci. Eng. 883(1), 012028 (2020)

28. Krutov A., Norkulov B., Uljaev F., and Jamalov F. Results of a numerical study of currents in the vicinity of a damless water intake. IOP Conf. Ser. Mater. Sci. Eng. 1030, 012121 (2021).

29. Bazarov D., Markova I., Raimova I., Sultanov Sh. Water flow motion in the vehicle of main channels. IOP Conf. Ser. Mater. Sci. Eng. 883, 012025 (2020).

30. Matyakubov B., Begmatov I., Raimova I. and Teplova G. Factors for the efficient use of water distribution facilities. IOP Conf. Ser. Mater. Sci. Eng. 883, 012025 (2020). 